Berliner Weltliteraturen 



\section{Berliner Weltliteraturen}

Internationale literarische Beziehungen in Ost und West nach dem Mauerbau

Herausgegeben von

Jutta Müller-Tamm 
Gefördert durch die Deutsche Forschungsgemeinschaft (DFG) im Rahmen der Exzellenzstrategie des Bundes und der Länder innerhalb des Exzellenzclusters Temporal Communities: Doing Literature in a Global Perspective - EXC 2020 - Projekt-ID 390608380.

ISBN 978-3-11-073831-5

e-ISBN (PDF) 978-3-11-073349-5

e-ISBN (EPUB) 978-3-11-073359-4

DOI https://doi.org/10.1515/9783110738315

\section{(cc) BY-NC-ND}

Dieses Werk ist lizenziert unter der Creative Commons Attribution-NonCommercialNoDerivatives 4.0 International Lizenz. Weitere Informationen finden Sie unter http://creativecommons.org/licenses/by-nc-nd/4.0/.

\section{Library of Congress Control Number: 2021941390}

\section{Bibliografische Information der Deutschen Nationalbibliothek}

Die Deutsche Nationalbibliothek verzeichnet diese Publikation in der Deutschen Nationalbibliografie; detaillierte bibliografische Angaben sind im Internet über http://dnb.dnb.de abrufbar.

(C) 2021 bei den Autoren, Zusammenstellung (c) 2021 Jutta Müller-Tamm, publiziert von Walter de Gruyter GmbH, Berlin/Boston

Dieses Buch ist als Open-Access-Publikation verfügbar über www.degruyter.com.

Cover: $\odot$ Renate von Mangoldt.

Druck und Bindung: $\mathrm{CPI}$ books $\mathrm{GmbH}$, Leck

www.degruyter.com 